\title{
DESAFIOS PARA A GARANTIA DO DIREITO À EDUCAÇÃO DOS ALUNOS EM SITUAÇÃO DE POBREZA: QUEM SÃO OS POBRES NO PLANO ESTADUAL DE EDUCAÇÃO DO TOCANTINS?
}

\author{
Juciley Silva Evangelista Freire \\ Universidade Federal do Tocantins (UFT), Palmas, Tocantins, Brasil \\ José Carlos da Silveira Freire \\ Universidade Federal do Tocantins (UFT), Palmas, Tocantins, Brasil
}

\begin{abstract}
Resumo: 0 presente artigo é parte da pesquisa realizada na Iniciativa Educação, Pobreza e Desigualdade Social, na Universidade Federal do Tocantins, que objetivou conhecer como as políticas educacionais pensam os sujeitos em situação de pobreza e extrema pobreza. Tem por objetivo apreender quem são os pobres no planejamento da educação que se materializa no Plano Estadual de Educação (20152025) do Tocantins. A metodologia utilizada foi a análise documental, fundamentada no referencial teórico que estabelece a relação entre educação, pobreza e desigualdade social e aquele que reafirma os Planos Educacionais como o eixo norteador das políticas educacionais. Os resultados demonstram que os sujeitos pobres, a quem são direcionadas metas e estratégias de equiparação das desigualdades educacionais, são os alunos beneficiários de programas de transferência de renda, quilombolas, indígenas, do campo e alunos com deficiências, ou seja, aqueles que historicamente vêm sendo alijados de seus direitos mais fundamentais, entre eles a educação.

Palavras-chave: Políticas Educacionais. Pobreza. Desigualdade Social. Plano Estadual de Educação do Tocantins.
\end{abstract}

\section{INTRODUÇÃO}

O Projeto de pesquisa As políticas educacionais no contexto das desigualdades sociais e da situação de pobreza e extrema pobreza no estado do Tocantins, vinculado ao Programa Nacional Educação, Pobreza e Desigualdade Social (EPDS), desenvolvido pela Secretaria de Educação Continuada, Alfabetização, Diversidade e Inclusão (SECADI), do Ministério da Educação (MEC), partiu das seguintes indagações: quem são, onde e como vivem os alunos em situação de pobreza e extrema pobreza no estado do Tocantins? Como as políticas educacionais pensam esses sujeitos, seus contextos e faz a mediação do enfrentamento dessas condições para a garantia do direito à educação?

Considerando esses questionamentos, o objetivo geral da pesquisa foi apreender como as crianças e jovens em situação de pobreza e extrema pobreza, especificamente os alunos do Programa Bolsa Família, são pensados e incorporados nas políticas educacio 
nais no Estado do Tocantins. Para tanto, delineamos como objetivos específicos: conhecer a realidade socioeconômica e educacional do estado do Tocantins no período de 2010 a 2017; caracterizar o perfil socioeconômico e educacional dos estudantes beneficiários do Programa Bolsa Família matriculados na escola pública de educação básica do Tocantins; identificar e analisar, no Plano Estadual de Educação (2015-2025), quem são os sujeitos e quais as políticas propostas para a garantia do direito à educação das crianças e jovens em situação de pobreza e extrema pobreza; e, identificar e analisar como esses sujeitos pobres e extremamente pobres são incorporados nas políticas da educação básica do estado do Tocantins.

Para alcançar estes objetivos foram desenvolvidas pesquisas bibliográfica e documental. Na pesquisa bibliográfica realizou-se leitura e síntese de referencial teórico sobre a relação entre educação, pobreza e desigualdade social no Brasil. Para a pesquisa documental, foi produzida uma guia de documentação e leitura para análise do Plano Estadual de Educação do Tocantins (PEE 2015-2025), cujo objetivo foi identificar nesse documento, nas metas e estratégias propostas para garantia do direito à educação, quem são as crianças e jovens em situação de pobreza e extrema pobreza.

Neste texto apresentamos, na primeira seção, a discussão sobre a pobreza e a desigualdade social e sua relação com a educação, apontando os desafios para a garantia do direito à educação. A segunda seção apresenta discussão sobre o papel do planejamento e da gestão educacional no equacionamento das desigualdades sociais e educacionais e atendimento aos estudantes em situação de pobreza, tomando os planos de educação como centrais no desenvolvimento das políticas educacionais. A terceira apresenta e discute os dados do Plano Estadual de Educação do Tocantins, considerando as metas e estratégias que mais diretamente tratam das ações para o enfrentamento das desigualdades sociais e educacionais. Nas considerações finais, destacam-se as contribuições e desafios das estratégias propostas para o enfrentamento da pobreza e desigualdades sociais.

PoBREZA, DESIGUALDADE SOCIAL E SUA RELAÇÃO COM A EDUCAÇÃO: DESAFIOS PARA GARANTIA DO DIREITO À EDUCAÇÃO

Pobreza é um fenômeno social, passível de análises empíricas, teorizações, classificações, identificação de suas causas e mensuração dos seus níveis, graus e consequências na vida objetiva e subjetiva das pessoas que vivenciam cotidianamente situações marcadas pela privação de carências básicas, como alimentos, renda, moradia, proteção à saúde, acesso à educação, e também a negação de direitos fundamentais para a dignidade humana e a liberdade. Além disso, as pessoas em situação de pobreza passam por constrangimentos, humilhações, violências e impedimentos no desenvolvimento de suas capacidades físicas, intelectuais ou morais.

A literatura especializada que trata a temática da pobreza é ampla, e a aborda a partir de diversas matrizes teórico-conceituais. Segundo Duarte (2012), é possível observar uma "axiologia da pobreza", que se divide entre as perspectivas liberal, socialista, moralista e técnica. Segundo a autora, 
FREIRE, J. S. E. $;$ FREIRE, J. C. S.

\begin{abstract}
a perspectiva liberal entende a pobreza como fruto de diferenças pessoais hierarquizantes que legitimam a coexistência das desigualdades sociais. A perspectiva socialista parte do pressuposto de que a pobreza é fruto de dinâmicas estruturais, da luta de classes e é um problema de toda a sociedade. A perspectiva moralista tem por fundamento o preconceito e juízo de valor que aceita a pobreza e a legitima, responsabilizando os pobres por essa condição. A técnica calcula e determina os pobres para apresentá-los ao Estado. Essa última tem regido parte da literatura sobre o tema e também a formulação de políticas públicas (DUARTE, 2012, p.228).
\end{abstract}

A perspectiva técnica é a que tem despontado mais expressivamente nos estudos acadêmicos e nas publicações oficiais. Ela tem finalidades diversas, orientandose para a formulação de políticas públicas sociais, para uso comparativo em estudos internacionais, para identificação e classificação dos pobres entre os não pobres, ou para responder às orientações de organismos internacionais (BELLUZO, 2014).

Segundo Lavinas (2003), "na acepção mais imediata e generalizada, pobreza significa falta de renda ou pouca renda". Essa concepção amplamente difundida e utilizada, baseia-se na quantificação, ou seja, destaca o predomínio de sua "expressão como carências monetárias" e proporciona "sua equivalência conceitual quase 'imediata' aos indicadores de rendimento familiar" (BELLUZZO, 2014, p. 24).

Essa perspectiva de medição e identificação da pobreza, baseada em indicadores de renda, pauta-se metodologicamente pela definição de linhas de pobreza e de extrema pobreza, que fixam patamares econômicos mínimos para a sobrevivência humana, a partir do qual se define quem é extremamente pobre, vivendo no limite da indigência, quem é pobre e quem não é pobre. No Brasil, a linha da pobreza está definida atualmente no limite de renda per capita entre $R \$ 85,00$ (oitenta e cinco reais) até $R \$ 170,00$ (cento e setenta reais) mensais, e a linha da extrema pobreza numa renda per capita de $\mathrm{R} \$ 85,00$ (oitenta e cinco reais) mensais (BRASIL, 2017).

A abordagem da pobreza baseada em indicadores de rendimentos tem a qualidade de evidenciar que a distribuição da riqueza é menos um problema do plano meramente econômico e mais uma expressão da forma de apropriação dessa riqueza no âmbito das relações sociais, trazendo para o centro do debate as questões sociais e políticas. Seu mérito é "a preocupação com a preservação da vida humana em contextos adversos" (BELLUZZO, 2014, p.24). Seu limite, contudo, alerta Belluzo (2014), "é a prevalência da garantia da manutenção da reprodução básica como fator privilegiado para a identificação da pobreza" (p.24), ou seja, a consideração apenas das carências ligadas à manutenção do corpo físico e não de outros bens e necessidades ligados ao modo de vida geral de uma determinada sociedade.

No contraponto a essa compreensão da pobreza como sinônimo de sobrevivência e sua definição apenas em termos de renda, surge a perspectiva que aborda a pobreza como um fenômeno multidimensional e complexo, referindo-se "não apenas a privações em termos de necessidades materiais de bem-estar, mas também à negação de oportunidades de se levar uma vida dentro de padrões aceitáveis socialmente" (CODES, 2008, p.23). Nessa abordagem, os fatores socioeconômicos, políticos e as relações sociais que incidem sobre a pobreza estão todos inter-relacionados. Segundo Codes (2008), 


\begin{abstract}
A multiplicidade de carências e penúrias impostas àqueles que vivem em situações de pobreza faz com que suas existências possam ser prematuramente encurtadas, além de duras, doloro sas e perigosas. Em suas manifestações subjetivas, o fenômeno provoca nas pessoas sentimentos de impotência diante de seus destinos, de falta de esperança, de vulnerabilidade, de insegurança e de falta de poder político. Além disso, como a pobreza não se esgota nos aspectos materiais e individuais, mas inclui as relações sociais, como o acesso ao trabalho e à assistência, as abordagens multidimensionais abarcam ainda dimensões sociais e mesmo políticas relacionadas a essa questão (p.23-24).
\end{abstract}

Nessa perspectiva multidimensional, para análise da pobreza são considerados desde fatores materiais, políticos e sociais até aqueles subjetivos que afetam os sentimentos e as capacidades individuais das pessoas em situação de privações diversas.

Todas essas concepções de pobreza levam à questão da desigualdade social, ou seja, ao entendimento de que a pobreza existe porque a distribuição da riqueza e a garantia de direitos fundamentais em uma determinada nação são desigualmente realizadas criando estratos sociais que não têm acesso ou têm acesso muito limitado aos bens produzidos socialmente e outros que acessam plenamente esses recursos. 0 Brasil figura entre os países mais desiguais do mundo ${ }^{1}$, mas não é um país pobre, no sentido dos recursos e de riquezas produzidas. Segundo Barros, Henriques e Mendonça (2000, p. 123) "o Brasil não é um país pobre, mas um país com muitos pobres" e "que os elevados níveis de pobreza que afligem a sociedade encontram seu principal determinante na estrutura da desigualdade brasileira - uma perversa desigualdade na distribuição da renda e das oportunidades de inclusão econômica e social".

Apesar da tendência verificada nas últimas décadas de redução da desigualdade de renda no Brasil, dados recentes sobre a estrutura da desigualdade social no país demonstram uma elevada concentração da riqueza entre os $10 \%$ mais ricos, que se apropriaram de $61 \%$ do crescimento econômico no período entre 2001 e 2015, enquanto que nesse mesmo período os $50 \%$ mais pobres se apropriaram de apenas $18 \%$ da riqueza produzida. Nesse contexto, o 1\% mais rico, ou seja, o topo da pirâmide social continua se apropriando de mais de $23 \%$ da riqueza total (OXFAM, 2017, p. 19).

A redução da desigualdade foi observada na base social mais empobrecida. Nos últimos 40 anos, a contar da promulgação da Constituição de 1988 até 0 ano de 2015, a desigualdade econômica teve uma redução "de $37 \%$ para menos de $10 \%$ a parcela de população brasileira abaixo da linha da pobreza" (OXFAM, 2017, p. 19). "Considerando os últimos 15 anos, o Brasil retirou da pobreza mais de 28 milhões de pessoas, ao mesmo tempo em que a grande concentração de renda no topo se manteve estável" (Idem, p.19).

Essa realidade significa ainda um padrão inaceitável de desigualdade, que requer a intervenção do Estado por meio de políticas públicas para combater sua forma econômica e todas as suas consequências sociais. A redução na desigualdade verificada nos últimos anos teve impactos em várias dimensões que não apenas a da renda. Neste artigo, queremos evidenciar os desafios postos para outras dimensões da vida social na redução das desigualdades e da situação de pobreza, no caso, a educação. Segundo a Oxfam: 
FREIRE, J. S. E. $;$ FREIRE, J. C. S.

A redução de desigualdades permite aumentar o acesso a direitos básicos. Dentro do Brasil, quanto menor a desigualdade de renda, maior a garantia a serviços essenciais como oferta de água ou de médicos, menores as taxas de mortalidade infantil e maior a expectativa de vida ao nascer. Combater desigualdades é também o caminho para vivermos em uma sociedade menos violenta, já que a exclusão social está diretamente relacionada ao aumento da violência, seja na cidade ou no campo. Por fim, a boa saúde de uma democracia depende de sociedades igualitárias: quanto maior a desigualdade e a interferência indevida de elites na definição de políticas, menor é a crença das pessoas na capacidade da democracia melhorar suas condições de vida, e menor é a crença na democracia em si (OXFAM, 2017, p.17).

As políticas de enfrentamento da situação de pobreza, da desigualdade social e da garantia de direitos sociais a todos os cidadãos no Brasil são recentes e têm sido desenvolvidas por meio de programas e ações focalizadas na população pobre e extremamente pobre. Segundo Duarte (2011), para o enfrentamento da pobreza, o Estado se utiliza das políticas sociais para "preservar bem-estar, estabilidade social e certo grau de coesão" (DUARTE, 2011, p.3). No contexto de enfrentamento da desigualdade e da redução da pobreza no Brasil os fatores que mais contribuíram, segundo a Oxfam (2017, p. 12), foram "a estabilização da economia e da inflação, o aumento real do salário mínimo e da formalização do mercado de trabalho, o aumento do gasto social em educação e em programas de transferência direta de recursos".

Essa intervenção estatal, contudo, não tem sido efetiva no ataque aos condicionantes estruturais que produzem as desigualdades econômica e social e reproduzem as condições de pobreza e extrema pobreza no país, mantendo-as em patamares muito altos, pois segundo a Oxfam (2017) os desafios para alteração substantiva desse cenário estão ligados

\begin{abstract}
à redistribuição de renda e riqueza no País, como o estabelecimento de uma política tributária justa, a melhoria da qualidade de serviços públicos, a reversão da concentração fundiária, além da inclusão educacional de adolescentes e jovens em idade universitária (sobretudo jovens negros) - para citar alguns (OXFAM, 2017, p.12).
\end{abstract}

No que concerne à educação, a inserção da população em situação de pobreza na escola ocorreu tardiamente no Brasil, e foi caracterizada pelo fracasso escolar e por uma ampliação para menos, sobretudo da qualidade da educação ofertada aos mais pobres (ALGEBAILE, 2009 apud DUARTE, 2011, p. 4).

Quando olhamos para a história de nosso país, vemos que o acesso à educação foi marcado por fortes desigualdades: ora pelo não acesso ao sistema escolar, ora pela exclusão dentro do próprio sistema ou, ainda, pelo acesso a padrões diferentes de qualidade educacional (SAMPAIO; OLIVEIRA, 2015, p.512).

A pobreza persiste dentro das escolas, nos noticiários e em diversos estudos sociais. Segundo Arroyo (2012, p. 6), nas salas de aula "essa realidade fica evidenciada pelos corpos famintos e empobrecidos de milhões de crianças e adolescentes que chegam às escolas, as quais são, em muitos casos, igualmente pobres". Concordamos com Duarte (2011) quando afirma que 


\begin{abstract}
A desigualdade escolar entre ricos e pobres fere preceitos constitucionais ao mesmo tempo em que afronta a perspectiva das oportunidades e atua como explicação capaz de legitimar as próprias desigualdades econômicas. Análises sobre indicadores sociais permite inferir que há forte correlação entre situação de pobreza e fracasso escolar - distorção idade/série, evasão e baixo IDEB - permitindo afirmar que os indicadores de fracasso escolar e baixa escolaridade nos dirigem aos mesmos lugares dos indicadores de vulnerabilidade social e pobreza (DUARTE, 2011, p.1).
\end{abstract}

Os adultos, os jovens e as crianças que vivem em condições de pobreza ou extrema pobreza protagonizam um cenário histórico de exclusão educacional ou baixa escolaridade (CURY, 2002; SAMPAIO; OLIVEIRA, 2015), em contraponto aos indicadores educacionais mais altos das classes sociais favorecidas economicamente, conforme observamos na tabela 1.

Tabela 1 - Escolaridade média da população brasileira de 18 a 29 anos, por renda familiar per capita (em anos de estudo)

\begin{tabular}{c|c|c|c|c|c|c|c|c|c|c}
\hline $\begin{array}{c}\text { Anol } \\
\text { Renda Familiar }\end{array}$ & 2005 & 2006 & 2007 & 2008 & 2009 & 2011 & 2012 & 2013 & 2014 & 2015 \\
\hline $25 \%$ mais pobres & 6,3 & 6,6 & 6,8 & 7,1 & 7,3 & 7,6 & 7,9 & 8,1 & 8,3 & 8,5 \\
\hline $25 \%$ mais ricos & 11,6 & 11,8 & 11,8 & 11,9 & 12,1 & 12 & 12,2 & 12,2 & 12,3 & 12,4 \\
\hline
\end{tabular}

Fonte: Elaboração própria a partir de indicadores disponíveis no Observatório do PNE

As taxas de escolaridade dos $25 \%$ mais pobres são inferiores às dos $25 \%$ mais ricos em toda a série histórica do período entre 2005 e 2015, na faixa etária entre 18 a 29 anos de idade. Apesar do aumento progressivo verificado na escolaridade média dos $25 \%$ mais pobres saindo de 6,3 anos para 8,5 anos no período de uma década, fruto das políticas sociais e educacionais do período, ainda é tímido o avanço se considerarmos que não chega ao patamar dos 11,6 anos dos mais ricos no início da série considerada. Esse é um exemplo claro de como a desigualdade socioeconômica é um dos condicionantes da desigualdade educacional. Essa desigualdade no atendimento educacional associada à desigualdade econômica, contudo, abrangem várias outras faixas de idade, conforme podemos observar no gráfico 1 abaixo: 
Gráfico 1 - Taxa de atendimento educacional por faixa etária e quartil de renda familiar per capita em 2013

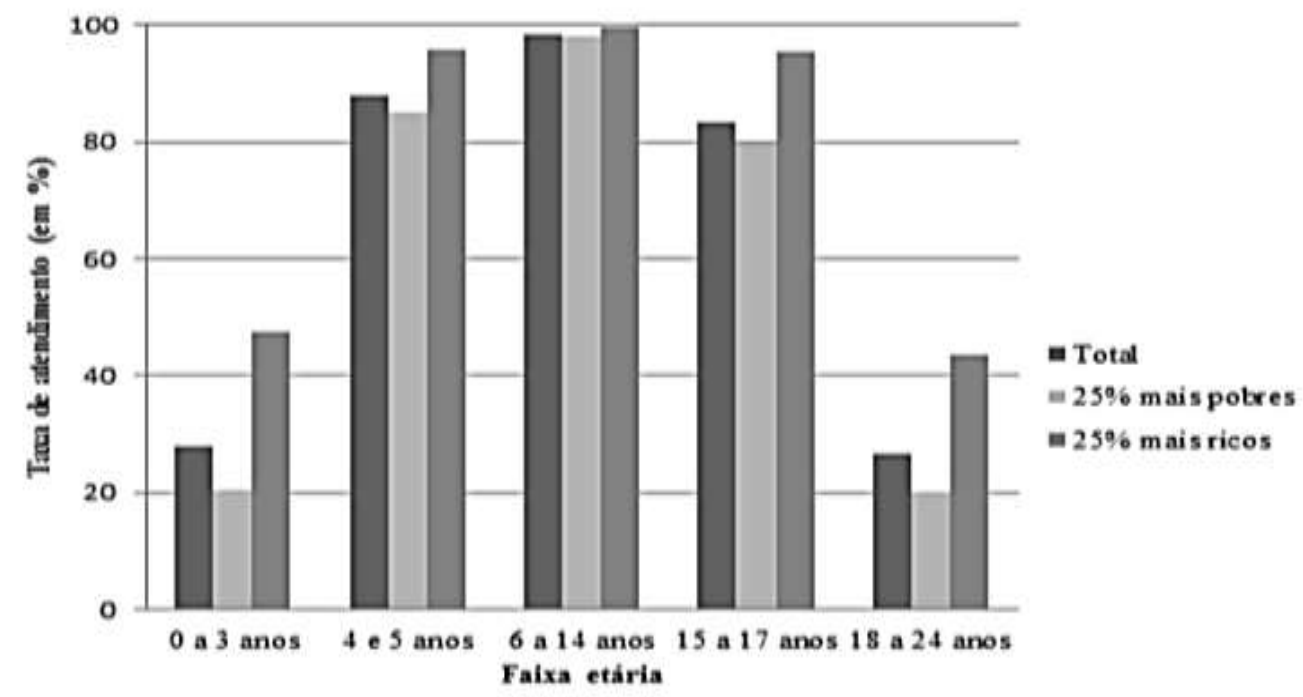

Fonte: Pnad/IBGE/Observatório do PNE

Os maiores níveis de desigualdade no atendimento educacional entre ricos e pobres podem ser observados nas faixas de 0 a 3 anos e de 18 a 24 anos, conforme já detalhado acima. Essas taxas por faixas etárias são independentes das etapas educacionais cursadas, mas na organização atual da educação brasileira correspondem às etapas de Educação Infantil e do Ensino Superior, aonde as diferenças nas taxas de atendimento educacional chegam a quase o dobro em favor dos mais ricos. No caso da educação infantil, de 0 a 3 anos, no ano considerado (2013), a taxa de atendimento no quartil mais pobre correspondia a menos de $20 \%(19,6)$, enquanto que entre o quartil mais rico era de $48,6 \%$, mais que o dobro (OBSERVATÓRIO do PNE).

\section{PlanOS DE EDUCAÇÃO NO ENFRENTAMENTO DA POBREZA E DAS DESIGUALDADES SOCIAIS}

Diante desse cenário de desigualdades, as políticas educacionais não podem abster-se de pensar essa realidade e estabelecer ações para combatê-la.

O Plano Nacional de Educação (BRASIL, 2014), aprovado em 2014 para o decênio 2014-2024, apresenta algumas metas e estratégias para enfrentamento desse cenário de desigualdade educacional e da pobreza (SAMPAIO; OLIVEIRA, 2015; GARCIA; HILLESHEIM, 2017; DOURADO, 2016). A meta 8 do PNE é a que mais diretamente trata da equiparação no atendimento educacional entre ricos e pobres, ao estabelecer a elevação da "escolari 
dade média da população de 18 a 29 anos, de modo a alcançar, no mínimo, 12 anos de estudo, no último ano de vigência do Plano, para as populações do campo, da região de menor escolaridade no país e para os $25 \%$ mais pobres, e igualar a escolaridade média entre negros e não negros declarados". A meta 9 do PNE articula-se com essa meta no combate à desigualdade ao propor a elevação da taxa de alfabetização da população acima de 15 anos, erradicar o analfabetismo absoluto e reduzir em $50 \%$ a taxa de analfabetismo funcional até o final da vigência do PNE (DOURADO, 2016, p. 30; BRASIL, 2014).

Segundo Dourado (2016, p. 30), essas metas são conexas e devem se "articular com a educação de jovens e adultos (EJA), a educação do campo, quilombola, indígena e especial", ou seja, modalidades de educação direcionadas a grupos so ciais historicamente excluídos economicamente e do acesso a bens culturais e direitos sociais.

Além dessas metas observamos que algumas estratégias do Plano Nacional de Educação também destacam o enfrentamento da questão da pobreza e da desigualdade social ao se referirem aos desafios de ampliar o acesso à Educação Infantil e ao Ensino Superior. Segundo Saraiva e Oliveira (2017, p. 516), “o sistema público visa diminuir essas desigualdades, buscando que as características pessoais de cada indivíduo interfiram menos em suas chances de cursá-los". Para esses autores,

Esta é a finalidade das estratégias 1.2 e 12.9 do PNE, cada uma referente a uma dessas etapas de escolarização: Estratégia 1.2) garantir que, ao final da vigência deste PNE, seja inferior a $10 \%$ (dez por cento) a diferença entre as taxas de frequência à educação infantil das crianças de até 3 (três) anos oriundas do quinto de renda familiar per capita mais elevado e as do quinto de renda familiar per capita mais baixo; [...] Estratégia 12.9) ampliar a participação proporcional de grupos historicamente desfavorecidos na educação superior, inclusive mediante a adoção de políticas afirmativas, na forma da lei (SARAIVA; OLIVEIRA, 2017, p. 516).

As proposições do PNE, tomado como o eixo articulador das políticas educacionais, desde o planejamento, da gestão até à avaliação, têm importância crucial para 0 enfrentamento das desigualdades sociais e das desigualdades escolares.

Segundo Arroyo (2011, p. 82), é preciso indagar às políticas educacionais "pelas consequências políticas dessas formas de pensar as desigualdades que se pretendem corrigir". Segundo o autor:

Uma consequência preocupante: desviar o foco das análises, do sistema escolar e de suas desigualdades, desde as condições físicas, de recursos, até as pedagógicas. Quanto mais as avaliações colocam o foco na condição desigual que levam os educandos mais tem sido secundarizadas as análises das desigualdades entre as escolas e no interior dos sistemas escolares. Sobretudo mais nos distanciamos das análises que destacaram, em décadas ainda tão próximas, o papel reprodutor das desigualdades que o sistema desigual teve e tem em nossa história. Ao condenar os alunos e seus coletivos de origem inocentamos o sistema, o Estado e suas instituições. Inocentamos a história de produção das desigualdades (ARROYO, 2011, p. 82). 
FREIRE, J. S. E. $;$ FREIRE, J. C. S.

Partindo dessas considerações, objetivamos conhecer como as políticas educacionais do Estado do Tocantins têm pensado os sujeitos pobres e desiguais no planejamento de suas políticas. Ou seja, se a maioria das crianças e jovens pobres adentram as escolas públicas e é dever do Estado oferecer-Ihes as condições igualitárias de acesso, permanência e conclusão dos seus estudos, quais têm sido as estratégias pensadas para oferecer essas condições? E quem são os sujeitos que necessitam dessas políticas? Como eles são pensados pelos instrumentos de planejamento dessas políticas educativas?

\section{Plano ESTAdUAL DO TOCANTINS: QUEM SÃO OS ALUNOS POBRES?}

O Plano Estadual de Educação do Estado do Tocantins (PEE - 2015-2025), aprovado em julho de 2015, na forma da Lei 으 2.977/2015, traz em seu escopo princípios e diretrizes que o orientam, dentre as quais destacamos a erradicação do analfabetismo, a universalização do atendimento escolar, a superação das desigualdades educacionais, com ênfase na promoção da cidadania e na erradicação de todas as formas de discriminação, a garantia de recursos públicos em educação com proporção que assegure atendimento às necessidades de expansão, com padrão de qualidade e equidade, e, ainda, a promoção dos princípios do respeito aos direitos humanos, à diversidade e à sustentabilidade socioambiental (TOCANTINS, 2015).

O Plano Estadual de Educação complementa o Plano Nacional de Educação, contemplando todas as metas previstas neste. Observa-se profundas semelhanças entre as proposições da Lei 13.005/2015 - PNE e a Lei n. 2.977/2015 - PEE/TO.

As metas de 1 a 5 do Plano Estadual de Educação tratam da garantia do acesso à educação básica em todas as suas etapas e modalidades. Observa-se que estão contempladas, nas estratégias relacionadas às metas acima referidas, medidas que dizem respeito à superação das desigualdades educacionais, principalmente para os grupos sociais que historicamente vivenciam a situação de pobreza e desigualdade social, que aparecem no Plano Estadual de Educação através das seguintes determinações: "populações do campo", "povos indígenas", "comunidades quilombolas", "beneficiários de programas de transferência de renda", "itinerantes", "alunos em situação de vulnerabilidade social", descritos nas estratégias 1.8, 3.1, 3.8, 4.7, 7.2, 7.3, 7.5, 13.12, 14.4 e 14.8.

A Meta 7 do PEE, que equivale à Meta 8 do PNE, é a que mais diretamente referese ao enfrentamento da pobreza e da desigualdade social, quando propõe alcançar, no período de vigência do Plano, no mínimo 12 anos de estudos dos jovens entre 18 e 29 anos pertencentes às populações do campo, aos $25 \%$ mais pobres da população tocantinense, e a igualar a escolaridade média entre negros e não negros. Ela cita a população do campo, os pobres e os negros como os mais afetados pela situação de pobreza e desigualdade social que, neste caso, se reveste de desigualdade no acesso ao direito à educação em todos os seus níveis, etapas e modalidades. Leva em conta, portanto, diferenças raciais, territoriais e de renda (SANTOS, 2016) e também etária, considerando apenas a parte da população jovem, isto porque a 
a juventude pobre experimenta condições sociais e de acesso educacional diversa daquela vivenciada pelos de maior renda; aqueles que residem no campo lidam com desafios e assumem identidades distintas daquelas dos jovens que vivem nas áreas urbanas, mais especificamente, nos grandes centros; os jovens negros apresentam, no geral, condições socioeconômicas distintas das experimentadas pelos que se declaram brancos (SANTOS, 2016, p.12).

O jovem pobre no Estado do Tocantins carrega em sua trajetória histórica grandes déficits de escolaridade. Enquanto a média de estudo da população geral de 18 a 29 anos de idade no Tocantins era de 9.9, em 2014, entre os 25\% mais pobres da população essa média era de apenas 8.1 anos, conforme podemos observar na tabela 24 abaixo. 0 aspecto positivo que se pode observar nesses dados é o crescimento constante dos anos de escolaridade dentro da série histórica, que iniciou em 2004 com irrisórios 5.6 anos de estudos para os mais pobres, um crescimento de 2,5 pontos percentuais em 10 anos, ritmo insuficiente para alcançar a meta estabelecida de 12 anos de estudo para esse grupo de pessoas. Nesse passo, no máximo se alcançará 10 anos de estudo para os mais pobres em 2024.

Tabela 2: Escolaridade média (em anos de estudo) da população de 18 a 29 anos pertencente aos 25\% mais pobres, no Brasil, na Região Norte e no Tocantins - 2004-2014

\begin{tabular}{|c|c|c|c|c|c|c|c|c|c|c|c|}
\hline \multirow{2}{*}{$\begin{array}{l}\text { Região/ } \\
\text { UF }\end{array}$} & \multicolumn{10}{|l|}{ Ano } & \multirow{2}{*}{$\begin{array}{l}\text { Variação } \\
\text { (p.p.) }\end{array}$} \\
\hline & 2004 & 2005 & 2006 & 2007 & 2008 & 2009 & 2011 & 2012 & 2013 & 2014 & \\
\hline Brasil & 5.6 & 5.8 & 6.2 & 6.4 & 6.7 & 7.0 & 7.3 & 7.6 & 7.8 & 8.0 & 2.4 \\
\hline Norte & 5.1 & 5.3 & 5.5 & 6.0 & 6.2 & 6.2 & 6.6 & 6.9 & 7.3 & 7.6 & 2.5 \\
\hline Tocantins & 5.6 & 6.1 & 6.2 & 6.6 & 7.1 & 7.0 & 7.3 & 7.5 & 8.0 & 8.1 & 2,5 \\
\hline
\end{tabular}

Fonte: elaboração própria a partir do Relatório do 10 ciclo de Monitoramento das Metas do PNE -2014 a 2016, Inep 2016.

Nas estratégias da Meta 7 observamos também a presença de outros sujeitos sociais, ou populações tradicionais, tais como os indígenas e os quilombolas, que estão fora da escola e com defasagem idade-série (7.2). Esses sujeitos também aparecem nas Metas 1, 3, 4, 5, 13 e 14 como aqueles a quem se destinam estratégias de enfrentamento à desigualdade de acesso à educação.

Essa realidade, no entanto, não é exclusiva do Tocantins, a literatura aponta seu caráter histórico, conforme discorre Moll $(2016$, p.1):

A história da educação escolar no Brasil é marcada pelas mesmas desigualdades que nos constituem como sociedade. Os degredados pela pobreza no campo e nas cidades e, também, muitas vezes, pela sua condição étnico-racial, só tardiamente começaram a ter acesso ao sistema educativo. Essa inclusão tardia veio somada à baixa qualidade das condições materiais e pedagógicas para sua permanência e aprendizagem na escola. 
As estratégias propostas no âmbito do Plano Estadual de Educação do Tocantins, para o decênio 2015-2025, apresentam-se como reparadoras de uma situação de marginalização e exclusão de parcelas da população tocantinense que historicamente foram excluídas do acesso aos direitos sociais mais básicos a um "justo e digno viver" (ARROYO, 2015), sobretudo no que diz respeito ao acesso, permanência e conclusão da educação escolar com qualidade. E não estamos falando de minorias, mas de parcelas significativas de sujeitos que vivenciam a situação de pobreza, independentemente de sua origem étnica, cultural ou racial. Ou seja,

ao tratarmos da relação entre educação e pobreza, não estamos falando de minorias. Estamos dizendo que grande parte da população inserida na escola pública brasileira traz consigo as demarcações da condição social centrada no recorte de renda (ser beneficiário de programa de transferência de renda) (YANNOULAS; GARCIA, 2017, p. 31).

No caso do estado do Tocantins, observamos que estes sujeitos pobres carregam também as marcas de identidades sociais, culturais e raciais, quando, por exemplo, no Plano Estadual de Educação as estratégias direcionadas ao combate às desigualdades sociais e ao enfrentamento da pobreza se referem aos povos campesinos, aí incluídos os indígenas, os quilombolas e os itinerantes.

Um aspecto a ser destacado é que esses sujeitos e a sua realidade social precisam ser pensados não somente na dimensão da quantidade de anos de estudos, como propõem a meta 7 e a meta 8 que trata da erradicação do analfabetismo que afeta sobretudo os jovens de 15 anos ou mais pertencentes à parcela mais pobre da população. A dimensão qualitativa da educação, ou seja, o acesso a uma educação de qualidade social precisa ser levado em conta. E qualidade passa pelo acesso e permanência numa escola com possibilidades concretas de aprendizagem, passa, portanto, pela existência de infraestrutura adequada às atividades educativas, à formação dos professores e condições de trabalho e valorização da carreira, aos recursos pedagógicos e tecnológicos que auxiliem no processo ensino-aprendizagem de todos os alunos e alunas. Tudo isso se consegue com investimento financeiro direcionado a políticas educacionais e a políticas sociais que objetivem melhorar as condições de vida dessa população pobre.

Nesse aspecto, o financiamento da educação adquire importância, pois para se conseguir alcançar as tímidas metas quantitativas associadas à qualidade da educação oferecida aos mais pobres será preciso ampliar os percentuais de investimento. No entanto, o que vemos é uma política regressiva de congelamento dos gastos públicos a partir da aprovação da EC no 95/2016, que aqui no estado do Tocantins repercutiu negativamente com a revogação por parte do governo estadual à estratégia 24.5 do PEE que previa a ampliação de recursos para a educação na ordem de $0,5 \%$ a cada ano de vigência do Plano, que seria acrescido ao percentual de $25 \%$ dos recursos vinculados constitucionalmente, chegando ao final do decênio (2015-2025) a um aumento de 5\% nesse percentual (TOCANTINS, 2017).

Vemos, portanto, que com essa medida do governo o PEE parece perder seu potencial de corrigir as desigualdades educacionais entre pobres e ricos, quando recursos necessários à ampliação das políticas educacionais são vetados, podendo implicar a continuidade da desigualdade educacional e social dos sujeitos na condição de pobreza 
e extrema pobreza, que no caso aqui apresentado são os beneficiários de programas de transferência de renda, os alunos do campo, os indígenas, quilombolas e itinerantes.

\section{CONSIDERAÇÕES FINAIS}

O Plano Estadual de Educação do Tocantins apresenta metas e estratégias relativas ao enfrentamento das desigualdades educacionais e sociais, bem como para garantia do acesso e permanência na escola aos sujeitos em situação de pobreza e extrema pobreza, fazendo referência ou apresentando como destinatários dessas estratégias os seguintes sujeitos: os alunos em situação de pobreza que são beneficiários dos programas de transferência de renda, os povos do campo, os indígenas, os quilombolas, os itinerantes e as pessoas com deficiências.

Assim, observam-se metas e estratégias que reconhecem esses grupos e propõem-se ações sistemáticas voltadas para a educação escolar indígena, a educação afrodescendente, a educação quilombola, a educação do campo, a educação de pessoas com deficiências, transtornos globais do desenvolvimento, altas habilidades e/ou superdotação, e o acesso e permanência dos alunos/populações beneficiárias dos programas de transferência de renda. Esse reconhecimento é importante para o enfrentamento dos diversos tipos de desigualdades, de classe, étnico-raciais, de gênero, entre outras. O reconhecimento desses grupos como sujeitos de direitos impõe ao Estado o desenvolvimento de políticas públicas voltadas ao enfrentamento das históricas desigualdades e formas de exclusão a que são submetidos em todas as regiões do país, e em maior proporção nas regiões norte e nordeste.

Artigo recebido em: 01/11/2018

Aprovado para publicação em: 23/03/2019

\section{CHALLENGES FOR THE GUARANTEE OF THE RIGHT TO EDUCATION OF STUDENTS IN POVERTY SITUATION: WHO ARE THE POOR IN THE STATE EDUCATION PLAN OF TOCANTINS?}

ABSTRACT: This article is part of the research carried out in the Education, Poverty and Social Inequality Initiative at Federal University of Tocantins, which aimed to know how educational policies percieve people in situations of poverty and extreme poverty. Its objective is to understand who are the poor in the planning of education that materializes in the State Education Plan (20152025) of Tocantins. The methodology used was documentary analysis, based on the theoretical framework that establishes the relationship between education, poverty and social inequality, and one that reaffirms the Educational Plans as the guiding axis of educational policies. The results show that the poor people, to whom goals and strategies of equalization of educational inequalities are directed, are beneficiaries studies of income transfer programs, quilombolas, natives, those in the countryside and students with disabilities, that means, those who, historically, have being kept from their most fundamental rights, among them is education

KEYWORDS: Educational Policies. Poverty. Social inequality. State Education Plan of Tocantins. 
FREIRE, J. S. E. $;$ FREIRE, J. C. S.

DESAFÍOS PARA LA GARANTÍA DEL DERECHO A LA EDUCACIÓN DE LOS ALUMNOS EN SITUACIÓN DE POBREZA: ¿QUIÉNES SON LOS POBRES EN EL PLAN ESTATAL DE EDUCACIÓN DE TOCANTINS?

RESUMEN: El presente artículo es parte de la investigación realizada en la Iniciativa Educación, Pobreza y Desigualdad Social, en la Universidad Federal de Tocantins, que objetivó conocer cómo las políticas educativas piensan a los sujetos en situación de pobreza y extrema pobreza. Tiene por objetivo aprehender quiénes son los pobres en la planificación de la educación que se materializa en el Plan Estatal de Educación (2015-2025) de Tocantins. La metodología utilizada fue el análisis documental, fundamentada en el referencial teórico que establece la relación entre educación, pobreza y desigualdad social y aquel que reafirma los Planes Educativos como el eje orientador de las políticas educativas. Los resultados demuestran que los sujetos pobres, a quienes se dirigen metas y estrategias de equiparación de las desigualdades educativas, son los alumnos beneficiarios de programas de transferencia de renta, quilombolas, indígenas, los del campo y alumnos con discapacidades, o sea, aquellos que históricamente se están alejando de sus derechos más fundamentales, entre ellos la educación.

PALABRAS CLAVE: Políticas Educativas. Pobreza. Desigualdad social. Plan Estatal de Educación de Tocantins.

\section{NOTA}

1) Segundo a Oxfam (2017) no "último Relatório de Desenvolvimento Humano do Programa das Nações Unidas para o Desenvolvimento (Pnud) o Brasil é o 10ํo país mais desigual do mundo, num ranking de mais de 140 países!" ( $p .21$ ).

\section{REFERÊNCIAS}

ARROYO, M. Políticas educacionais e desigualdades: à procura de novos significados. Educ. \& Soc., Campinas, v.31, n.113, p. 1381-1416, out./dez., 2010.

- Os coletivos empobrecidos repolitizam os currículos. In: ; SILVA, M. R. da (Org.). Corpo - infância: exercícios tensos de ser criança: por outras pedagogias dos corpos. Petrópolis: Vozes, 2012. p. 23 -54.

BARROS, R.P. de; HENRIQUES, R.; MENDONÇA, R. Desigualdade e pobreza no Brasil: retrato de uma estabilidade inaceitável. Revista Brasileira de Ciências Sociais, vol. 15, no 42, fev. 2000.

BRASIL. Ministério do Desenvolvimento Social. Programa Bolsa Família: O que é; Como funciona. Disponível em <http://mds.gov.br/assuntos/bolsa-familia/o-que-e/comofunciona>. Acesso em: 12 nov. 2017.

BRASIL. Lei no 13.005, de 25 de junho de 2014. Aprova o Plano Nacional de Educação - PNE e dá outras providências. Brasília, 2014. Disponível em: 
<https://www.planalto.gov.br/ccivil_03/_ato2011-2014/2014/lei/l13005.htm>. Acesso em: 05 out. 2017.

CURY, C. R.J . A Educação Básica no Brasil. Educ. Soc., Campinas, v. 23, n. 80, p. 168-200, set. 2002.

DOURADO, L. F. Plano Nacional de Educação: política de Estado para a educação brasileira. Brasília: Inep, 2016.

DUARTE, Natália de Souza. Política educacional e o percurso escolar da população em situação de pobreza. Anais do XI CONLAB, Salvador: UFBA,7 a 11 ago. 2011.

FERNANDES, M. D. E.; GOUVEIA, A. B. Acompanhando a meta 20 do PNE 2014-2024: tendências a partir de dez casos municipais. Textura, Canoas, v. 19, n.40, p.95-115, maio/ago. 2017.

GARCIA, A. V.; HILLESHEIM, J. Pobreza e desigualdades educacionais: uma análise. Educar em Revista, Curitiba, Brasil, v. 33, n. especial 2, p. 131-147, set. 2017.

LAVINAS, L. Pobreza e exclusão: traduções regionais de duas categorias da prática. Econômica, v.4, no 1, p.25-59, jun. 2002.

OBSERVATÓRIO DO PNE. Disponível em <http://www.observatoriodopne.org.br /metaspne/1-educacao-infantil/estrategias/1-2-combate-a-desigualdade/dossie-localidades >. Acesso em: 18 nov. 2017.

PALMAS. Lei n² 2.238 de 19 de janeiro de 2016, institui o Plano Municipal de Educação de Palmas. Diário Oficial do Município de Palmas, № 1424, terça-feira, 19 de janeiro de 2016. PALMAS. Lei ํㅡ 2.238, de 19 de janeiro de 2016. (Alterado pelo Decreto no 2.243, de 23/03/2016). Institui o Plano Municipal de Educação de Palmas e dá outras providências. Palmas: 2016. Disponível em: <http://legislativo.palmas.to.gov.br/media/leis/leiordinaria-2.238-2016-01-19- 3-6-2016-15-44-42.pdf >. Acesso em: 05 out. 2017.

SAMPAIO, G. T. C.; OLIVEIRA, R. P. de. Dimensões da desigualdade educacional no Brasil. Revista Brasileira de Política e Administração da Educação - RBPAE, v. 31, n. 3, p. 511 - 530, set./dez. 2015.

SANTOS, M. P. G. dos. Pobreza, desigualdade, exclusão e cidadania: correlações, interseções e oposições. In: ___. O Estado e os problemas contemporâneos. Florianó polis: Departamento de Ciências da Administração: UFSC; [Brasília]: CAPES: UAB, 2009, p. 16-25. 
FREIRE, J. S. E. $;$ FREIRE, J. C. S.

TOCANTINS. Lei $n^{\circ} 2.977$, de 08 de julho de 2015, institui o Plano Estadual de Educação do Tocantins (2015-2025). Diário Oficial, no 4.411. Ano XXVII - Estado do Tocantins, Palmas, quinta-feira, 09 de julho de 2015.

YANNOLAS, S. C.; DUARTE, N. de S. Política educacional e o percurso escolar da população em situação de pobreza. Anais do XV Congresso Luso Afro Brasileiro de Ciências Sociais, Diversidades e Desigualdades, Salvador, UFBA, 07 a 10 de agosto de 2011.

Juciley Silva Evangelista Freire: Doutora em Educação, professora da UFT/Campus de Palmas, atua no curso de Pedagogia. Coordenadora do Núcleo de Estudo e Pesquisa em Educação, Desigualdade Social e Políticas Públicas - NEPED/UFT.

ORCID: https://orcid.org/0000-0001-9613-8108

E-mail: jucy@uft.edu.br

José Carlos da Silveira Freire: Doutor em Educação, professor da UFT/Campus de Palmas. Coordenador do Curso de Aperfeiçoamento em Educação, Pobreza e Desigualdade Social da UFT.

E-mail: crreire@uft.edu.br

Este periódico utiliza a licença Creative Commons Attribution 3.0, para periódicos de acesso aberto (Open Archives Iniciative - OAI). 